\title{
Effect of Heating Rate on the Development of Annealing Texture in Nonoriented Electrical Steels
}

\author{
Jong-Tae PARK, ${ }^{1,2)}$ Jerzy A. SZPUNAR ${ }^{11}$ and Sang-Yun CHA ${ }^{21}$ \\ 1) Department of Mining, Metals and Materials Engineering, McGill University, 3610 University Street, Montreal, Quebec, \\ Canada, H3A 2B2. $\quad$ 2) Technical Research Laboratories, POSCO, Pohang-shi, Kyungbuk, Korea. \\ E-mail: jerzy.szpunar@mcgill.ca
}

(Received on November 11, 2002; accepted in final form on May 12, 2003)

\begin{abstract}
The magnetic properties of nonoriented electrical steels are influenced by grain size and texture. During the final annealing process, heating rate, annealing temperature and time, and cooling rate are the main factors which can influence the formation of annealing texture. Among these parameters, heating rate is more effective in controlling texture development through changes in the recovery and recrystallization processes. Therefore, it can provide the means to decrease core loss and increase permeability. In nonoriented electrical steels with different initial grain sizes, the effect of heating rate on texture development during final annealing is examined, and the reasons for texture changes are discussed. The average grain size decreases with the increase in heating rate both in the coarse-grained and in the fine-grained specimens. In the coarse-grained specimen, the Goss texture is significantly strengthened but the $\{111\}\langle 112\rangle$ texture component is slightly weakened as heating rate increases. On the other hand, in the fine-grained specimen, the $\{111\}\langle 112\rangle$ intensity is greatly decreased but the Goss intensity is slightly increased as the heating rate increases. The heating rate up to the annealing temperature affects texture formation differently depending on the initial grain size prior to cold rolling. These differences are mainly related to the difference in the number of shear bands formed during cold rolling in grains having different sizes.
\end{abstract}

KEY WORDS: nonoriented electrical steels; annealing; heating rate; initial grain size; texture.

\section{Introduction}

Nonoriented electrical steels have been widely used as the core materials of motors and generators. For these applications low core loss and high permeability are required. The magnetic properties are mainly dependent on two metallurgical factors: grain size and texture. ${ }^{1,2)}$ Grain size control has been extensively investigated whereas texture control has received much less attention. Of the various processing steps, the final annealing is the most important since it is the last process to determine the grain size and texture of nonoriented electrical steels. During the annealing process, the heating rate, annealing temperature and time, and cooling rate are the main factors that influence the formation of the annealing texture. Among these processing parameters, the heating rate is the most effective in controlling texture formation through changes in recovery and recrystallization behaviors. Furthermore, an increase in the heating rate provides the means to decrease core loss and, at the same time, to increase permeability in nonoriented electrical steels. ${ }^{3,4)}$ However, until now rather contradictory results about the effect of heating rate on texture formation in steels have been reported ${ }^{5-11)}$ and the reason for the texture change which results from changes in the heating rate has not been clearly explained. Some researchers ${ }^{5-7)}$ suggested that a fast heating rate weakened (111) annealing texture while others found that it strength- ened (111) texture ${ }^{8)}$ or had no effect on the texture formation. ${ }^{9)}$ Another researcher ${ }^{10)}$ demonstrated that a fast heating rate increased the strength of $\{110\}\langle 001\rangle$ texture. Inagaki ${ }^{11)}$ proposed that the heating rate affected differently the formation of the annealing texture depending on the initial grain size prior to cold rolling in pure iron, and that annealing by rapid heating increased significantly the $\{110\}\langle 001\rangle$ texture component in coarse-grained specimens, whereas it did not nearly change the annealing texture in fine-grained specimens. Nonoriented electrical steels undergo or do not undergo $\alpha-\gamma$ phase transformation during hot rolling according to their silicon content because silicon is a strong ferrite former. In general, there is a $\alpha-\gamma$ phase transformation in $1 \%$ silicon steels whereas there is no phase transformation in $2 \%$ silicon steels. This difference in the phase transformation helps to obtain a big difference in initial grain size prior to cold rolling. In the present study, the effect of heating rate on texture development during the final annealing is examined in nonoriented electrical steels with different initial grain sizes containing $1 \%$ $\mathrm{Si}$ and $2 \% \mathrm{Si}$, respectively. Based on the results obtained, the reason for texture changes due to different heating rates is discussed.

\section{Experimental Procedure}

The starting materials were two kinds of hot bands that 
Table 1. Chemical compositions of specimens used in this study $(w t \%)$.

\begin{tabular}{|c|c|c|c|c|c|c|c|}
\hline $\mathrm{C}$ & $\mathrm{Si}$ & $\mathrm{Al}$ & $\mathrm{Mn}$ & $\mathrm{P}$ & $\mathrm{S}$ & $\mathrm{N}$ & \\
\hline 0.0050 & 1.0 & 0.27 & 0.26 & 0.0026 & 0.0050 & 0.0025 & $\begin{array}{c}\text { Fine-grained } \\
\text { specimen }\end{array}$ \\
\hline 0.0035 & 2.0 & 0.31 & 0.24 & 0.0018 & 0.0030 & 0.0020 & $\begin{array}{c}\text { Coarse-grained } \\
\text { specimen }\end{array}$ \\
\hline
\end{tabular}

have the chemical compositions shown in Table 1. In order to achieve a significantly different initial state prior to cold rolling, the hot bands containing $2 \% \mathrm{Si}$ were annealed at $1000^{\circ} \mathrm{C}$ for $5 \mathrm{~min}$. The initial average grain size obtained was $40 \mu \mathrm{m}$ for $1 \% \mathrm{Si}$ and $115 \mu \mathrm{m}$ for $2 \% \mathrm{Si}$. The specimens with different initial grain sizes were cold rolled to $0.5 \mathrm{~mm}$ by $75 \%$ reduction using a laboratory mill. After that, the cold rolled specimens were annealed at $850^{\circ} \mathrm{C}$ for $3 \mathrm{~min}$ at three different heating rates. The two heating rates were $10^{\circ} \mathrm{C} / \mathrm{s}$ and $30^{\circ} \mathrm{C} / \mathrm{s}$ (hereafter called fast heating), respectively, in the range from room temperature to $800^{\circ} \mathrm{C}$ and subsequently the heating rate was $5^{\circ} \mathrm{C} / \mathrm{s}$ up to $850^{\circ} \mathrm{C}$, in order to avoid any possible overheating. The third heating rate was $5^{\circ} \mathrm{C} / \mathrm{min}$ (hereafter called slow heating) in the range between room temperature and $850^{\circ} \mathrm{C}$. After soaking at $850^{\circ} \mathrm{C}$, all the specimens were cooled at the constant rate of $10^{\circ} \mathrm{C} / \mathrm{s}$ irrespective of the heating rate applied. The microstructures of all the specimens were observed on the cross sectional area parallel to the rolling direction using optical microscopy. A nital solution of $2 \%$ was used as an etchant. The average grain size at different heating rates was obtained using the image analyzer.

For pole figure measurement, the specimens were mechanically polished and then electropolished in a solution of $800 \mathrm{~mL}$ glacial acetic acid and $200 \mathrm{~mL}$ perchloric acid $\left(\mathrm{HClO}_{4}\right)$, in order to remove the deformation layer introduced during previous mechanical polishing. After electropolishing, the texture was measured at one eighth of the sheet thickness using a Siemens texture goniometer with Mo radiation. Three incomplete pole figures of (110), (200) and (211) were measured and the orientation distribution function (ODF) was calculated using TexTools, a commercial software for texture analysis.

\section{Results and Discussion}

\subsection{Effect of Heating Rate on Texture in Coarse- grained Specimen}

Figure 1 shows a change of the average grain size for different heating rates in the coarse-grained specimen. The average grain size decreases as the heating rate increases. However, the difference in grain size between specimens heated at $30^{\circ} \mathrm{C} / \mathrm{s}$ and $10^{\circ} \mathrm{C} / \mathrm{s}$ is negligible. The size of recrystallized grain is determined by both the nucleation and growth rates. ${ }^{12)}$ During the annealing process, less recovery takes place during fast heating than during slow heating so more stored energy is preserved in the specimen heated by fast heating before recrystallization commences. Higher stored energy increases the nucleation rate faster than the growth rate. ${ }^{12)}$ As a result, the annealing by fast heating leads to a smaller grain size than that by slow heating,

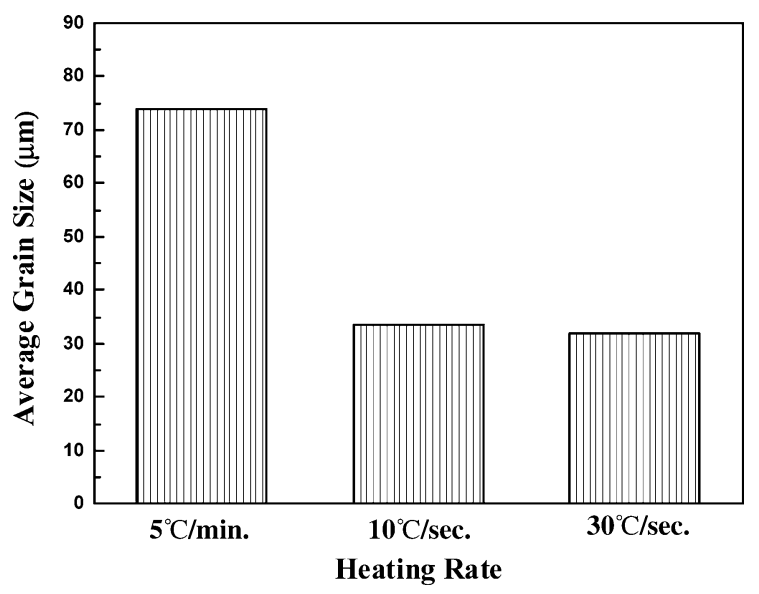

Fig. 1. Change of average grain size with heating rate in the coarse-grained specimens.

which is in agreement with the results of other researchers. $^{7,13)}$

The texture obtained for different heating rates is presented in the $\varphi_{2}=45^{\circ}$ section of the orientation distribution function in Fig. 2. It is clearly demonstrated that the heating rate has a significant effect on the developed texture. In the case of fast heating, a very strong $\{110\}\langle 001\rangle$ (Goss) texture develops and its intensity is higher for a heating rate of $30^{\circ} \mathrm{C} / \mathrm{s}$ than for $10^{\circ} \mathrm{C} / \mathrm{s}$. On the other hand, in the case of slow heating, the $\{111\}\langle 112\rangle$ component is dominant and $\{110\}\langle 114\rangle,\{001\}\langle 120\rangle$ and $\{111\}\langle 110\rangle$ components are weak. The major difference in texture changes with heating rate lies in the strength of the Goss component. The Goss component becomes strong during annealing by fast heating, whereas only a weak $\{110\}\langle 114\rangle$ component, $20^{\circ}$ away from ideal Goss orientation, is developed during annealing by slow heating.

Texture change with heating rate can be best illustrated by the $\varepsilon$-fibre because it includes all of the information about the major texture components, $\{110\}\langle 001\rangle$ and $\{111\}\langle 112\rangle$. The change of $\varepsilon$-fibre with heating rate is represented in Fig. 3. As the heating rate increases, the Goss component is strengthened, while the $\{111\}\langle 112\rangle$ component is weakened even though the difference is not very pronounced.

To understand these differences in texture shear band formation should be discussed. Shear bands are known as severely strained regions formed as a result of strain inhomogeneity due to structural instability during rolling deformation. ${ }^{14)}$ The formation of shear bands depends not only on deformation conditions but also on the chemical compositions, texture and microstructure of materials. Since the shear bands are preferential sites for nucleation, they should be considered of importance in the recrystallization process. In this research on recrystallization texture, ${ }^{15}$ ) the coarse-grained specimens have many shear bands in deformed grains having $\{112\}\langle 110\rangle,\{111\}\langle 110\rangle$ and $\{111\}\langle 112\rangle$ orientations. It was also demonstrated that new grains with Goss orientation are nucleated within shear bands. In addition, it was found that the new grains with Goss orientation are usually nucleated at the very early stage of recrystallization since the regions of shear bands have the highest stored energy and nucleation takes place 


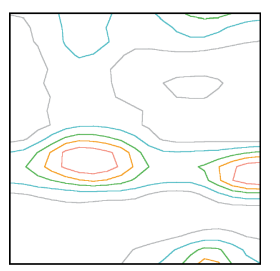

(a) $5^{\circ} \mathrm{C} / \mathrm{min}$.

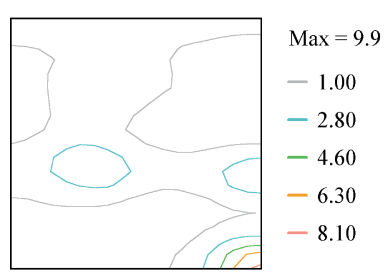

(c) $30^{\circ} \mathrm{C} / \mathrm{sec}$

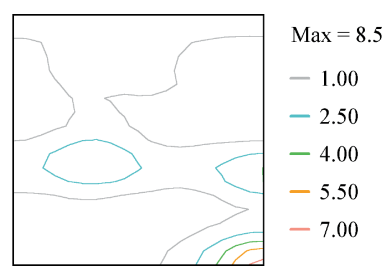

(b) $10^{\circ} \mathrm{C} / \mathrm{sec}$.

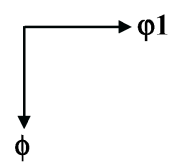

Fig. 2. $\varphi_{2}=45^{\circ}$ section of ODF at different heating rates in the coarse-grained specimen: (a) $5^{\circ} \mathrm{C} / \mathrm{min}$, (b) $10^{\circ} \mathrm{C} / \mathrm{s}$, (c) $30^{\circ} \mathrm{C} / \mathrm{s}$.

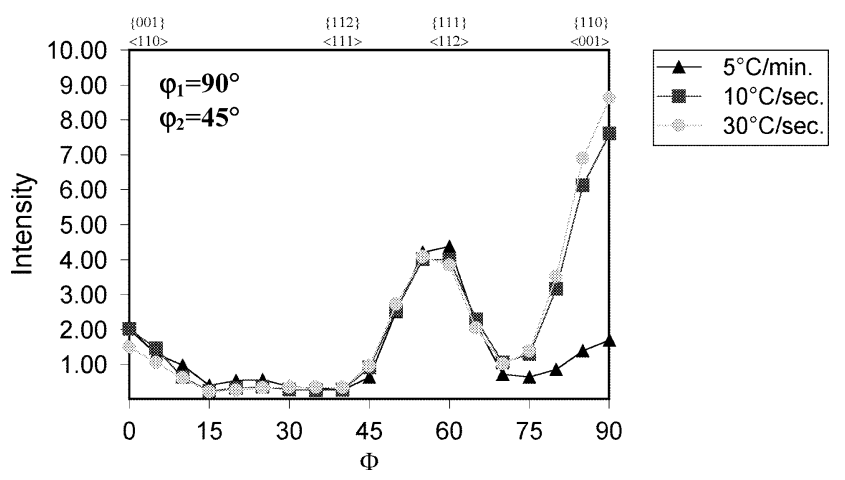

Fig. 3. Change of $\varepsilon$-fibre texture with heating rate in the coarsegrained specimen.

earlier in high stored energy regions. Consequently, shear bands turned out to play a very important role in determining the recrystallization texture, in which the Goss and $\{111\}\langle 112\rangle$ components are dominant. Moreover, slow heating increases the amount of recovery before the recrystallization progresses. It was also pointed out that the differences in residual stored energy among various texture components are reduced as recovery proceeds. ${ }^{16)}$ Based on these two facts, one can claim that when heating rate is slow, the new grains with Goss orientation have a lower chance of nucleating and then of consuming the surrounding deformed matrices during annealing. As a result, the Goss component decreases in strength and the resultant texture becomes more random. The $\{111\}\langle 112\rangle$ texture component, which is competing with the Goss during the progress of recrystallization, is strengthened.

\subsection{Effect of Heating Rate on Texture in Fine-grained Specimen}

The average grain size at three different heating rates in the fine-grained specimen is presented in Fig. 4. Similarly as in the coarse-grained specimen, the average grain size decreases with the increase in heating rate. This phenomenon can be explained in a similar way as mentioned above.

The texture change observed with an increase in the heating rate is illustrated in Fig. 5 using the $\varphi_{2}=45^{\circ}$ sec-

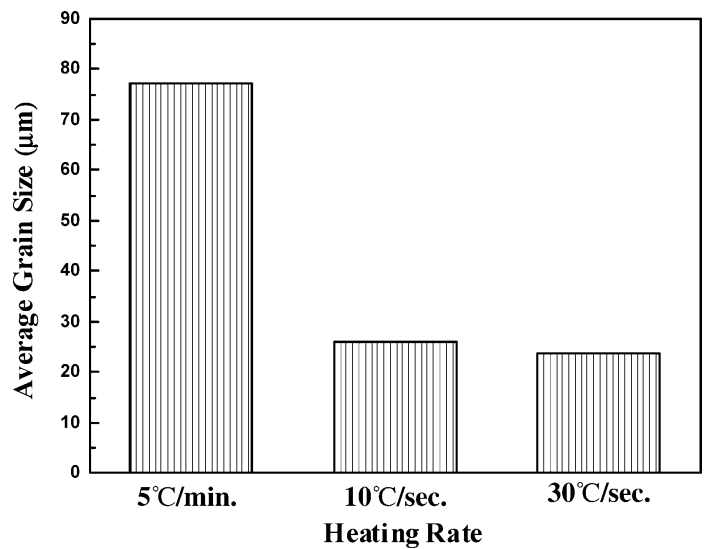

Fig. 4. Change of average grain size with heating rate in the finegrained specimen.

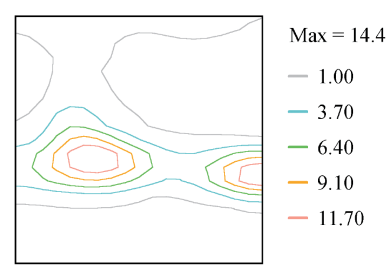

(a) $5^{\circ} \mathrm{C} / \mathrm{min}$.
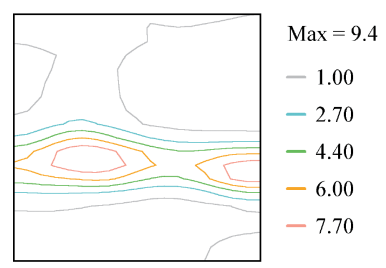

(c) $30^{\circ} \mathrm{C} / \mathrm{sec}$.

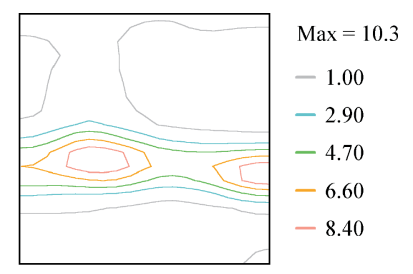

(b) $10^{\circ} \mathrm{C} / \mathrm{sec}$.
Fig. 5. $\varphi_{2}=45^{\circ}$ section of ODF at different heating rates in the fine-grained specimen: (a) $5^{\circ} \mathrm{C} / \mathrm{min}$, (b) $10^{\circ} \mathrm{C} / \mathrm{s}$, (c) $30^{\circ} \mathrm{C} / \mathrm{s}$.

tions of the orientation distribution function. The textures are characterized by a strong $\gamma$-fiber with a maximum at $\{111\}\langle 112\rangle$, for all heating rates. However, the intensity of the $\{111\}\langle 112\rangle$ component changes with increasing heating rate and shows a significant difference between fast heating and slow heating. The heating rate also influences the development of the Goss component, and the Goss intensity increases slightly with the increase in the heating rate. The difference in texture formation for different heating rates can be more clearly represented by the $\varepsilon$-fiber, as illustrated in Fig. 6. As the heating rate increases, the $\{111\}\langle 112\rangle$ component is significantly weakened, while the Goss component is slightly strengthened.

Examination of the microstructure indicates that shear bands are more likely to form in materials with a coarse grain size prior to cold rolling. ${ }^{17-19)}$ In our previous research, ${ }^{15)}$ it has been demonstrated that the $\{111\}\langle 112\rangle$ texture component is stronger during the whole recrystallization process than any other components, and the shear bands are preferential nucleation sites of the new Goss grains. It is obvious that in the fine-grained specimen having an average grain size of $40 \mu \mathrm{m}$ prior to cold rolling, the shear bands are much less formed and play a less important 


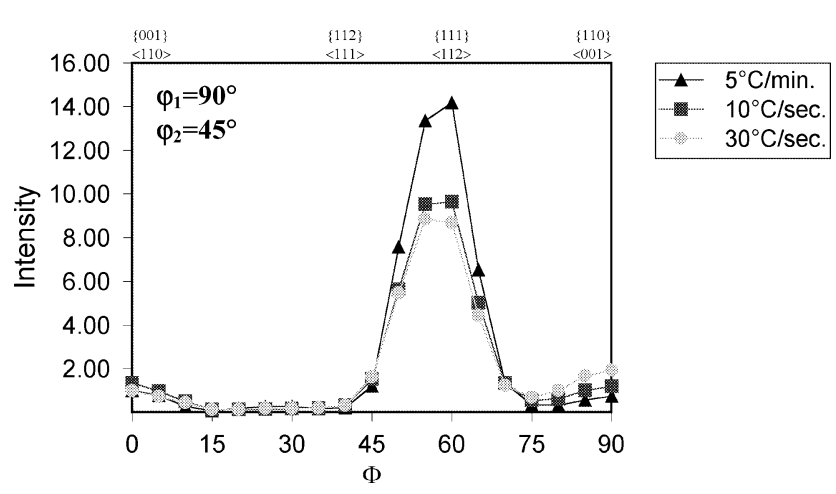

Fig. 6. Change of $\varepsilon$-fibre texture with heating rate in the finegrained specimen.

role in the formation of recrystallization texture than in the specimen with much larger grains. The nucleation of the Goss grains usually takes place earlier and the nuclei formed have a higher chance of growing at the expense of surrounding deformed matrices because the shear bands represent regions with the highest stored energy. However, since slow heating is associated with stronger recovery than fast heating, the difference in residual stored energy among various texture components may be reduced before recrystallization starts, ${ }^{16}$ ) and the Goss nuclei have therefore a lower chance of growing. In the meantime, the nuclei of $\{111\}\langle 112\rangle$ grains, the most dominant component from the early stage of recrystallization, grow by consuming their surrounding deformed matrices. ${ }^{15)}$ This may be considered the reason why the $\{111\}\langle 112\rangle$ intensity is greatly increased but the Goss intensity is decreased during slow heating.

The heating rate up to the temperature at which the specimen is annealed affects the texture formation depending on the initial grain size prior to cold rolling. In the coarsegrained specimen, fast heating greatly strengthens the Goss texture but slightly weakens the $\{111\}\langle 112\rangle$ texture whereas, in the fine-grained specimen, fast heating significantly decreases the $\{111\}\langle 112\rangle$ texture but slightly increases the Goss texture.

\section{Conclusions}

(1) The average grain size decreases with an increase in the heating rate both in the coarse-grained and in the fine-grained specimens.

(2) In the coarse-grained specimen, the Goss texture is significantly strengthened but the $\{111\}\langle 112\rangle$ texture component is slightly weakened as the heating rate increases. On the other hand, in the fine-grained specimen, the intensity of the $\{111\}\langle 112\rangle$ component is greatly reduced but the Goss intensity is slightly increased as the heating rate increases.

(3) The heating rate up to the annealing temperature affects texture formation differently depending on the grain size prior to cold rolling. These differences may be related to the number of shear bands formed in the cold rolled state.

\section{REFERENCES}

1) G. Lyudkovsky, P. K. Rastogi and M. Bala: J. Met., 38 (1986), 18.

2) E. T. Stephenson and A. R. Marder: IEEE Trans. Mag., 22 (1986), 101.

3) J. T. Park: Unpublished data

4) X. Duan, H. Huneus, T. Kochmann, K. Leuridan, R. Kaczmarek and F. Protat: J. Magn. Magn. Mater., 160 (1996), 133.

5) J. L. Lebrun, G. Maeder and P. Parniere: Proc. of 6th Int. Conf. on Textures of Materials, (1981), 57.

6) I. V. Alexandrov and G. J. Davies: Mater. Sci. Eng., 75 (1985), L1.

7) T. Senuma: Proc. of the 1st Joint Int. Conf. on Recrystallization and Grain Growth, ed. by G. Gottstein and D. A. Molodov, Germany, (2001), 1125.

8) M. Ferry, D. Muljono and D. P. Dunne: Proc. of 12th Int. Conf. on Textures of Materials, ed. by J. A. Szpunar, (1999), 991.

9) J. Stockemer and P. Vanden Brande: Proc. of the 1st Joint Int. Conf. on Recrystallization and Grain Growth, ed. by G. Gottstein and D. A. Molodov, Germany, (2001), 1131.

10) C. Dasarathy and R. C. Hudd: Z. Metallkd., 60 (1969), 853.

11) H. Inagaki: Z. Metallkd., 82 (1991), 265.

12) J. D. Verhoeven: Fundamentals of Physical Metallurgy, John Wiley \& Sons, USA, (1975).

13) E. Bommier and F. Moliexe: Unpublished results, IRSID.

14) F. J. Humphreys and M. Hatherly: Recrystallization and Related Annealing Phenomena, Pergamon Press, (1995).

15) J. T. Park: Ph. D. Thesis, McGill University, (2002).

16) C. J. E. Smith: Ph. D. Thesis, Birmingham University, (1968).

17) M. Hatherly: Proc. 6th Int. Conf. on Strength of Metals and Alloys, ed. by Gifkins, Pergamon Press, (1982), 1181.

18) A De Paepe, J. C. Herman and V. Leroy: Steel Res., 68 (1997), 479.

19) L. Lesne, H. Réglé, C. Maurice and J. H. Driver: RecrystallizationFundamental Aspects and Relations to Deformation Microstructure, 21st Risø Int. Symp., Risø National Laboratory, Denmark, (2000), 407. 